\title{
The Impact of the COVID-19 Pandemic on the Working Conditions, Employment, Career Development and Well-Being of Refugee Researchers
}

\author{
Ourania Tzoraki 1,*(D), Svetlana Dimitrova ${ }^{2, *}$, Marin Barzakov ${ }^{2}$, Saad Yaseen ${ }^{3}$, Vasilis Gavalas ${ }^{4}$, Hani Harb ${ }^{5}$, \\ Abas Haidari ${ }^{1}$, Brian P. Cahill ${ }^{6}{ }^{(D)}$, Alexandra Ć ulibrk ${ }^{1}{ }^{(D}$, Ekaterini Nikolarea ${ }^{7}$, Eleni Andrianopulu ${ }^{8}$ \\ and Miroslav Trajanovic ${ }^{9}$
}

check for updates

Citation: Tzoraki, O.; Dimitrova, S.; Barzakov, M.; Yaseen, S.; Gavalas, V.; Harb, H.; Haidari, A.; Cahill, B.P.; Ćulibrk, A.; Nikolarea, E.; et al. The Impact of the COVID-19 Pandemic on the Working Conditions,

Employment, Career Development and Well-Being of Refugee Researchers. Societies 2021, 11, 71. https://doi.org/10.3390/ soc11030071

Academic Editors: Sandro Serpa and Carlos Miguel Ferreira

Received: 14 May 2021

Accepted: 24 June 2021

Published: 1 July 2021

Publisher's Note: MDPI stays neutral with regard to jurisdictional claims in published maps and institutional affiliations.

Copyright: (c) 2021 by the authors. Licensee MDPI, Basel, Switzerland. This article is an open access article distributed under the terms and conditions of the Creative Commons Attribution (CC BY) license (https:// creativecommons.org/licenses/by/ $4.0 /)$.
1 Marine Sciences Department, University Hill, 81100 Mytilene, Greece; abas@marine.aegean.gr (A.H.); aculibrk@marine.aegean.gr (A.Ć.)

EURAXESS BHO, Sofia University, Dragan Tzankov, str. 1164, 1504 Sofia, Bulgaria; barzakov@fmi.uni-sofia.bg

3 Institut für Informationsmanagement und Unternehmensführung, Osnabrück University of Applied Sciences, Konrad-Adenauer 13, 49808 Lingen, Germany; s.yaseen@hs-osnabrueck.de

4 Department of Geography, University Hill, 81100 Mytilene, Greece; bgav@aegean.gr

5 German-Syrian Research Society, 60314 Frankfurt, Germany; hani.harb@ds-fg.de

6 Learning and Skills Analytics Group, Leibniz Information Centre for Science and Technology (TIB), 30167 Hannover, Germany; Brian.Cahill@tib.eu

7 School of Social Sciences, University Hill, 81100 Mytilene, Greece; anikolarea@aegean.gr

8 International Office, Bielefeld University, 33615 Bielefeld, Germany; eleni.andrianopulu@uni-bielefeld.de

9 Faculty of Mechanical Engineering, University of Nis, Aleksandra Medvedova 14, 18000 Nis, Serbia; miroslav.trajanovic@masfak.ni.ac.rs

* Correspondence: rania.tzoraki@aegean.gr (O.T.); svetlana@fmi.uni-sofia.bg (S.D.); Tel.: +30-22510-36840 (O.T.); +359-2-9308-200 (S.D.)

Abstract: The ongoing 'refugee crisis' of the past years has led to the migration of refugee researchers (RRs) to European countries. Due to the COVID-19 pandemic, RRs often had to work from home and/or to continue their social, cultural and economic integration process under new conditions. An online survey carried out to explore the impact of the pandemic on the refugee researchers showed that RRs found it difficult to adapt their everyday working life to the 'home' setting. The majority have had neither a suitable work environment at home nor the appropriate technology. Although they stated that they are rather pleased with the measures taken by the public authorities, they expressed concern about their vulnerability due to their precarious contracts and the bureaucratic asylum procedures, as the pandemic has had a negative impact on these major issues. The majority of RRs working in academia seem not to have been affected at all as far as their income is concerned, while the majority of those employed in other sectors became unemployed during the pandemic (58\%). Recommendations are provided to the public authorities and policy makers to assist RRs to mitigate the consequences of the pandemic on their life.

Keywords: COVID-19; refugee researchers (RRs); researcher at risk; scholars at risk; employment; pandemic; working from home; asylum procedure

\section{Introduction}

The outbreak of the Coronavirus disease COVID-19 has affected all the countries of the world, with 147 million infected and 3.1 million dead at the end of April 2021 [1]. Facing limited preparedness to control the spread of the virus, various governments adopted several public health strategies. The applied measures include enforcing complete or partial restrictions to financial and social activities, the so called "lockdowns", restricting international travel, social distancing and the adoption of hygiene practices (masking, hand disinfection) [2]. Academic events such as conferences and meetings have been taking 
place online. Schools and universities closed and started to give classes online. Business activity was restricted.

The COVID-19 pandemic has affected significant aspects of economic and social life, forcing millions of people to working from home (WFH) [3]. Since the start of the pandemic, almost $85 \%$ of knowledge workers in Europe made a shift to the WFH practice [4], even though they used to spend more than $80 \%$ of their working time in a central office environment [5].

At the same time, Europe faced the so called "refugee crisis", with 2.2 million arrivals in the period 2014-2020 in the South European countries and Germany to host almost half of the asylum seekers reaching Europe [6]. Scientists with academic and specialized knowledge (refugee researchers-RRs) who have left their country, seeking a safer life, have been trying to integrate into their host countries and continue their research careers.

RRs are a vulnerable part of the refugee community (very often waiting for asylum procedures to end). Due to the precarious nature of their research funding, they are strongly dependent on short-term scholarships or research grants that may have been expired during the pandemic, and many are without any financial support for their research, for instance, as they have been waiting for research funding applications to be evaluated. Moreover, RRs employed in industry or in the private sector are potentially in a more vulnerable position due to their generally less stable employment conditions and lower seniority on the job.

The objective of the current research is to explore how the COVID-19 pandemic has affected the working conditions, employment, career development and well-being of refugee researchers (RRs). The outcome of this research will evaluate the impact of the COVID-19 pandemic on refugee scientists' working life and provide recommendations for policy makers. A literature review, which follows, describes the impact of the COVID-19 pandemic on the WFH, on researchers working life and on refugee integration. Then in the section "material and methods" the methodology that was followed is analyzed and finally in the results are presented the main findings of the current research.

\subsection{Literature Review: WFH during the COVID-19 Pandemic}

Several studies have explored the challenges and opportunities that WFH presents, despite the fact that many of these studies present contradictory results; for instance, some studies have found an increase in work productivity [7] and others a decrease [8] or a heterogeneous effect [9]. Taking into account the rapid improvement of digital technology, team communication platforms (i.e., Zoom, Google Meet) and the special conditions of social distancing and "lockdowns", we examined the recent studies as well as whether and how the pandemic has provided a new challenge for WFH.

Research carried out in Norway to explore the share of jobs that can be carried out from home, found that only $38 \%$ of the Norwegian jobs can be considered as being conducive for WFH. The geographical and social context is crucial with urban areas having a higher ratio of WFH positions than rural areas, and vulnerable parts of the society (i.e., migrants, single parents, low qualified workers) have less likelihood to get such jobs [10]. A lower share of jobs with the WFH options is found in East Germany and a much higher share in urban areas, such as, Berlin, Darmstadt, Hamburg and Munich [11]. Analysis of data from several countries has shown that richer and more developed countries have had a higher number of jobs that can be run from home [10], whereas in regions with a low share of WFH jobs, a lower average income has been observed [11].

However, the COVID-19 pandemic may have a more negative impact on poorer districts [11]. The analysis of WFH in developing countries such as Peru, Costa Rica and Brazil has shown heterogeneity, and is strongly dependent on the type of work, the gender and the employee's skills, with educated workers and women having higher chances of being suitable for WFH [12]. In contrast, many studies have described the difficulties WFH presents for women with caring responsibilities for small children at home $[13,14]$. Moreover, employees with high technical skills and capacity to use digital communication software (i.e., Zoom, Skype) are better paid [15] than women and low skilled workers [16]. 
In general, the change in lifestyle habits and the mentally passive status of staying at home brought by the pandemic are more likely to deteriorate mental health and reinforce health inequalities in society, with people with low income being the most vulnerable. Symptoms of anxiety and depression became more prevalent due to the unsecure economic situation and the fear of loss of employment [17].

\subsection{Literature Review: Impact of COVID-19 on Researchers}

The academic community adapted to the COVID-19 pandemic restrictions with an almost complete shift to online working. More than $90 \%$ of life scientists reported making use of videoconferencing during the pandemic [18]. The majority of field studies and laboratory studies were postponed, and scientists found more time for data analysis, writing up scientific papers and preparing proposals to compete for research grants [18]. Many researchers shifted their research to contribute to combatting the COVID-19 pandemic through work on medicine, life sciences, biomedical engineering, or by studying the consequences of the pandemic on the social, political and economic life and the environment (i.e., reduction of industrial emissions, increase of wastes) [19,20]. More than 100,000 articles were published in 2020 about the pandemic, which represent $4 \%$ of global research output [21].

The pandemic affected various scientific disciplines in different ways. The decline in research time in "laboratory" sciences (i.e., chemistry, biology) was 30-40\% less than the pre-pandemic level due to the fact that this kind of research depends on physical presence in the laboratory and on expensive equipment, which cannot be replaced by any other means. In contrast, research fields that rely on information technology (IT), such as computer science, informatics and economics, experienced a much smaller decline in the research time from WFH. At the same time, many conferences shifted online, ensuring that young scientists can share their research findings for free or at lower cost, thus allowing them to maintain or expand their networks and form new collaborations [22]. This shift has provided the opportunity for scientists around the globe to attend e-seminars, and e-conferences, avoid time consuming and expensive travel, and greatly diminish their environmental footprint.

Administrative procedures were delayed due to the absence of the administrative staff from their offices with newly hired young struggling to deal with administrative procedures. However, the most vulnerable were scientists whose contracts ended during the pandemic. Although some universities (i.e., 30 universities in USA) extended work contracts for two months, in many cases researchers with precarious contracts lost their wage once their contracts ran out [22]. European Molecular Biology Organization (EMBO) was one of the first organizations that realized the problem, and acted to extend the scholarships of postdoctoral fellows by two months [23].

Social inequalities increased with the pandemic with women scientists found to be in a more vulnerable situation than men [24]. Due to the fact that female scientists have not had access to their "bench" laboratories, they have faced difficulties with organizing their time in WFH due to school closure, especially those with small children [18,22]. Research analyzing the proportion of women among first authors of scientific articles and preprints as well as the involvement in new projects found that the proportion declined during the lockdown [14].

\subsection{Literature Review: COVID-19 Effect on Refugee Integration}

The crisis has increased the social vulnerability of RRs and placed obstacles in the way of the integration process [25]. The refugee integration process is strongly related to the long-standing experience of the involved regions. For instance, Berlin, with its cosmopolitan character, offers advantageous conditions for the integration of highly skilled refugees in the labor market. In contrast, in smaller German cities there has been an absence of the institutional settings that operate as long-term points of contact, such as university societies and civil society organizations [26]. In Greece, the absence of any long-term integration strategy of refugees into the labor market has resulted in sporadic funding schemes that limit the mentoring and training activities towards employability provided by 
specific organizations, such as Civil Society Organizations and employment agencies [27]. In Sweden, highly skilled refugees have lower employment levels and relative earnings than the natives [28].

Highly skilled refugees are a minority in the "refugee crisis", to which little attention has been paid. Lack of information about the possible choices a refugee may have professionally or research-wise is a major obstacle to his or her integration into the workforce. The Science4Refugees initiative of the European Union gave birth to specific European progamssuch as the BRiDGE I and II projects [29], as well as the SCIREA project [30], which developed tools to train refugee researchers (RRs) for and inform them about possible career choices as well as to monitor their efforts to re-enter academia and/or the labor market.

COVID-19 complicated refugee integration in Germany due to concerns about health and financial risk [31]. The pandemic increased the feeling of uncertainty in refugees' everyday working life and diminished the mechanism and objectives to improve their working conditions [25]. Furthermore, internationally mobile scientists are more vulnerable due to the crisis. Almost half of them live alone, feel isolated and frustrated by frequent updates of the local regulations in a foreign language they may not understand well [18].

\section{Materials and Methods}

An online survey was conducted between December 2020 and January 2021. The participants in the survey were selected through convenience sampling, a type of non-probability sampling, where the sample is taken from a group of people easy to contact and reach. The pool was four networks of refugee researchers (RRs): the Bielefeld University RRs network, the University of the Aegean RRs network, the German-Syrian Research Association, and the Bridge II pilot Refugee Researchers peer group. The total population of these networks is more than 300 persons and comprises refugees mainly from the Middle East and Africa (Figure 1a). The questionnaire (which can be found in the Table S1 in the Supplementary file) was sent by email to everyone that was enlisted in the aforementioned networks (approximately 300 persons). The final sample (those who answered the questionnaire sent to them electronically) was 64 persons, the majority of which (82.8\%) were between 25 and 44 years old. Men were more numerous in our sample ( 43 males vs. 21 females). The sample is vulnerable to non-response bias (those who answered may differ in their answers from those who did not answer the questionnaire). However, the convenience sampling was the only method with which data could be collected from a plenitude of countries (the host countries of RRs) swiftly and relatively efficiently.

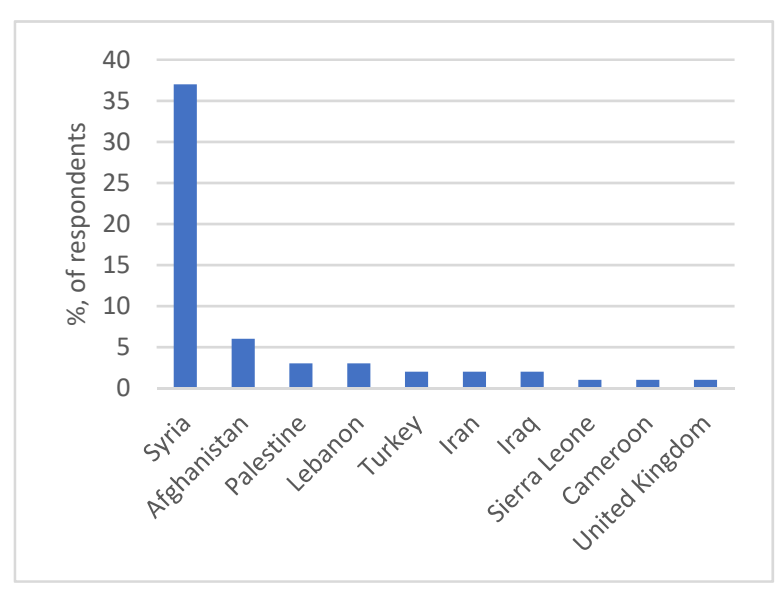

(a)

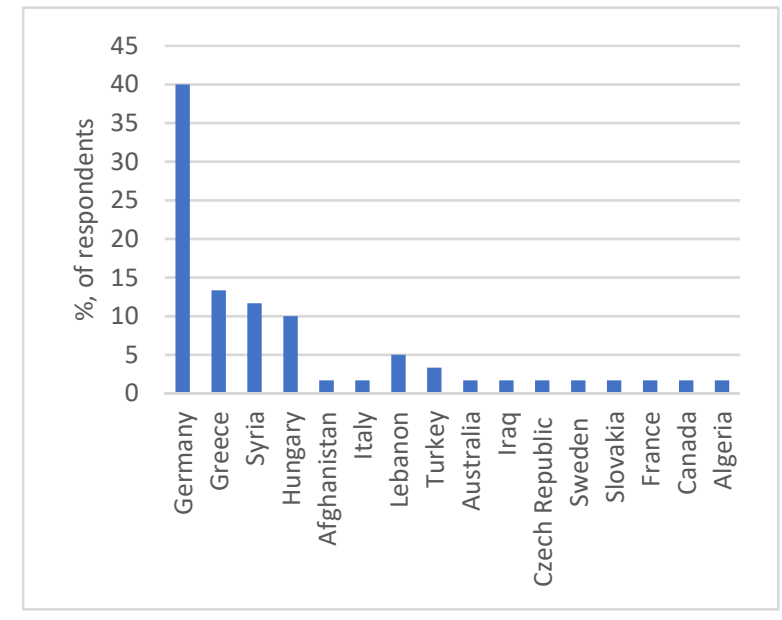

(b)

Figure 1. (a) Origin country of refugee researchers (RRs); (b) host country of RRs. 
Questionnaire and its validity: The questions selected were a synthesis of questions used on previous research surveys, which were studying the effect of the COVID-19 pandemic to the work, health, income of refugees as well as the adaptation level of employees to the WFH situation [4,32]. The survey of Cimpoeru et al. (2020) aimed to document the impact of new living conditions through the pandemic in Germany and Romania. The questions refer to refugees' level of concern about the pandemic as well as the extent to which it has affected their work, health, and income. Kelly's survey (2020) focused on analyzing the employee's ability to adapt to working from home, together with their relationship to available technology. The questionnaires of the above studies and the addition of the refugee's opinion on the delay of the procedures for asylum seekers constitute the framework of this survey (Table S1).

The questionnaire was created via Google Forms and was distributed in English to the aforementioned target group. Information about the scope of the survey was provided, the average amount of time needed to complete the survey and the considered personal data protection rules.

The analysis included the following demographic variables: nationality, country of destination, gender, age, educational level (check the highest available), and family status.

The refugees' economic status was characterized using two variables:

- employment (employed/unemployed/student/self-employed/working in the family business/entrepreneur/NGO); and

- income (living comfortably on present income/coping with the present income/finding it difficult with the present income).

The main variables for this analysis concern COVID-19 on the basis of five core questions, of which one has three subcategories and another has seven subcategories. The first question was "Taking into consideration the current situation of COVID-19, how worried are you according to the current crisis?". This question provides a means to assess how the COVID-19 pandemic has affected levels of anxiety and concern among refugees. A five-point Likert scale was used, starting at 1 with "Not worried at all" and ending at 5 with "Totally worried".

The second question, "To what extent do you feel affected by COVID-19 considering the following issues?", had three subcategories: Employment Status, Income and Health. Three responses were possible for each subcategory: "Not affected at all", "Moderately affected", "Strongly affected".

The effectiveness of authorities' responses to the COVID-19 pandemic was assessed in the third question: "In your opinion are the measurements taken by the public authorities efficient to reduce the spread of the virus in your current country?". A five-point Likert scale was used, starting at 1 with "Not at all efficient" and ending at 5 with "Very efficient".

The fourth question had seven subcategories: (a) the assessment of individual office workers of their own productivity, on being unable to work in their familiar office environment, at short notice and for an undefined amount of time; (b) the evolution of workers' attitudes to workplace technology since the onset of the COVID-19 crisis in Europe (March 2020); (c) whether emerging technologies have facilitated workers to at least have the same/more perceived levels of human-computer interaction.

The fifth question addresses how the COVID-19 pandemic delayed asylum procedures.

All variables are categorical, either nominal or ordinal in their scale of measurement. Frequency tables, presented as bar charts or pie-charts, were used for summarizing the data. Contingency tables were used to detect causal relationships between variables. The Pearson's chi-square test of independence was employed to establish non-random relationships, while measures of association (Cramer's V and Phi) were employed to detect causality. Marital status, educational level, age and working sector were considered as independent variables, which may or may not moderate the effects of the pandemic on the income, the working status and asylum procedures of the refugee researchers.

Practical implication design: Peer group can be defined as a group of people of similar interests or common characteristics, such as a group of people joining the same training 
scheme (i.e., students) or who found themselves in the same conditions (i.e., minor refugees in a collective accommodation center) or people who have common concern (i.e., a soccer team, job seekers, asylum seekers). The peer group composition and desires are temporary [33]. In general, RRs are organized in their own networks, mostly those of the same political and national background or from their former academic environment. What is missing is the opportunity to meet RRs from the same discipline and to better understand the local job market, to collaborate and share knowledge and build up peer mentoring relationships. A specific methodology was followed in the creation and operation (with physical and online meetings) of the pilot peer group of RRs in close collaboration with BRIDGE II partners and the German Syrian Research Society. The pilot group consists of 16 RRs as members with origin from seven countries: Yemen, Syria, Iraq, Iran, Afghanistan, Turkey and Cameroon. Eight members live in Greece, seven in Germany and one in Ireland. Two women participated in the peer group. The design of policy recommendations was based on the analysis and discussion of the survey results within three meetings of the "pilot peer group of RRs" that took place on 25 January 2021, 1 February 2021 and 15 February 2021.

\section{Results}

In this section, the results of the questionnaire survey are presented and analyzed. The main finding is that marital status, age and educational level do not play a substantial role in the income and the working status of RRs amidst COVID-19, given that all RRs are relatively well educated. The variable that exhibits the strongest effect of COVID-19 on income and employment status is the working sector, with those employed in the academic sector being the least affected by lockdown measures. In what follows, some descriptive statistics of the sample are presented and, subsequently, detailed results of the bivariate associations are given.

The first country of origin is Syria (37 respondents), followed by Afganistan (6), Palestine (3) and Lebanon (3) (Figure 1a). Generally, 95\% of the participants come from Asian and Middle Eastern Countries. The hosting countries are Germany (24 respondents), followed by Greece (8), Syria (7), Hungary (6) and Lebanon (3) (Figure 1b). Generally, 40\% of the participants are hosted in Germany. At this point, it should be noted that five refugees did not answer the questions regarding their country of origin and the hosting country, and, therefore, the aforementioned percentages (valid percent) correspond to a sample of 59 individuals. The majority of the participants are men (77\%), and they hold a master's degree $(42.2 \%$ ) or a PhD degree $(18.8 \%$ ) (Figure $2 \mathrm{a}$ ). In total, 30.5\% of the participants are students, $32.2 \%$ work in a research institute or at a university, $20.3 \%$ in a non-governmental organization (NGO) and, to a lesser extent, are entrepreneurs, self-employed, work in public administration or in the family business (Figure $2 b$ ).

The pandemic introduced changes in RRs' lives with $40.6 \%$ of the participants declaring that their employment status was negatively and strongly affected, while only $22 \%$ were not affected at all. (Figure 3a) As far as their health is concerned, $15.6 \%$ stated that were strongly affected by the pandemic (Figure 3b). The participants' level of uneasiness, interest and affection due to the current COVID-19 crisis on a 5-point Likert scale ranges from moderate $(32.8 \%)$ to high $(21.9 \%)$ up to very high $(28.1 \%)$. Many lost their job, friends, family or feel uncomfortable to face the changes in their daily life. A large minority of the RRs face difficulties with coping with their income (46.9\%).

The major challenges of the RRS to WFH are to deal with (a) lower productivity $(56.3 \%)$; (b) the loss of feeling part of a physical team $(45.3 \%)$; (c) keeping work and home life separate $(42.2 \%)$ (Figure 4$)$, since the majority of them $(59.4 \%)$ do not have enough space to set up a home office for remote work. Other studies agree that researchers' self-perceived productivity has been lowered during the lockdown [18]. As for the access to information technology devices, the majority of the respondents have had a personal computer $(84.4 \%)$ as well as access to online collaboration software $(60.9 \%)$, whereas a minority had a second display monitor $(23.4 \%$ ) or fast broadband speed (15.6\%) (Figure 5). 


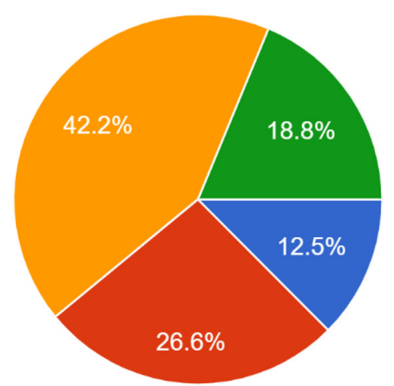

Associate's degree

Bachelor's Degree

Master's Degree

Doctoral degrees

(a)

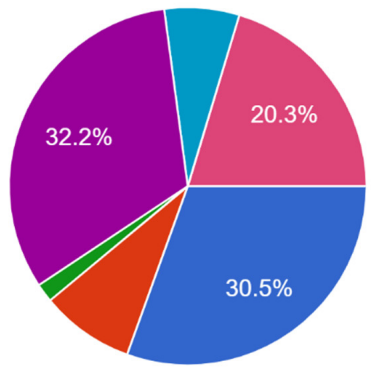

Student

Self-employed

Working in the family business

Entrepreneur

University/Research Institute

Public administration

NGO

(b)

Figure 2. (a) RRs' educational level; (b) RRs' working sector.

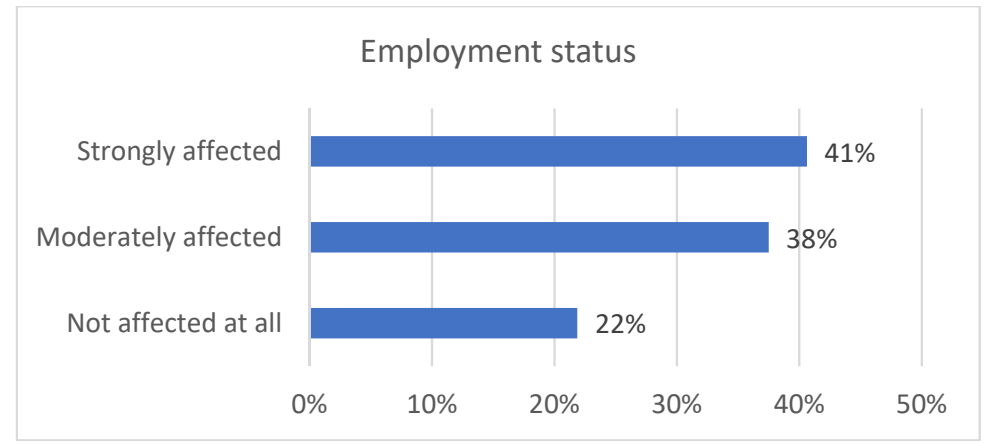

(a)

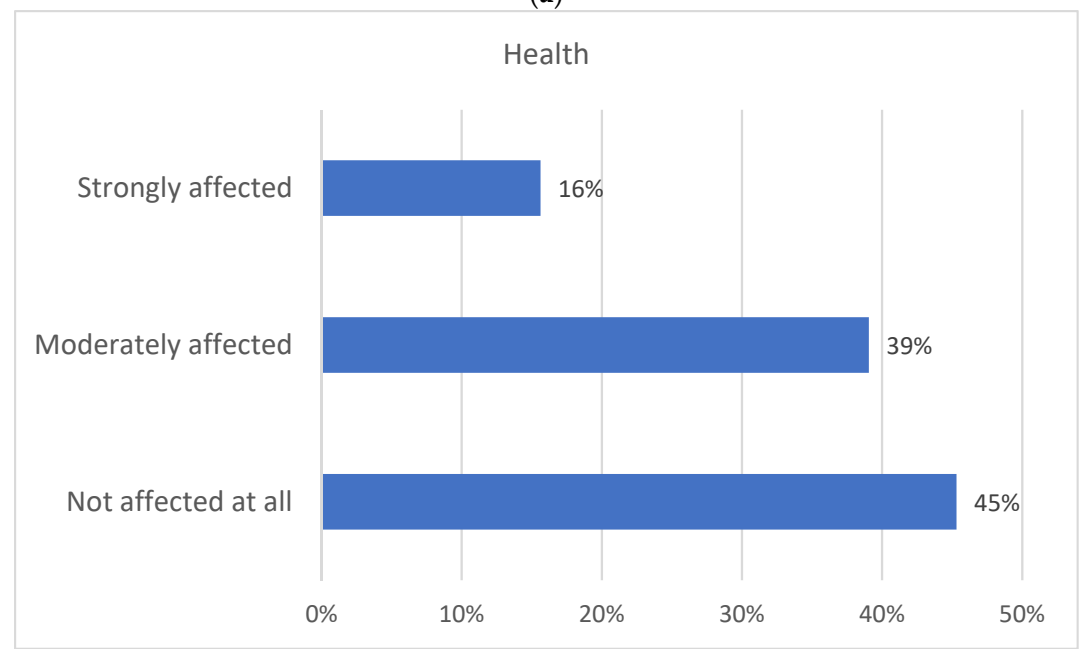

(b)

Figure 3. (a) Impact of the COVID-19 pandemic on RRs' employment; (b) impact of the COVID-19 pandemic on RRs' health. Source: online survey that took place between December 2020 and March 2021. N: 64. 


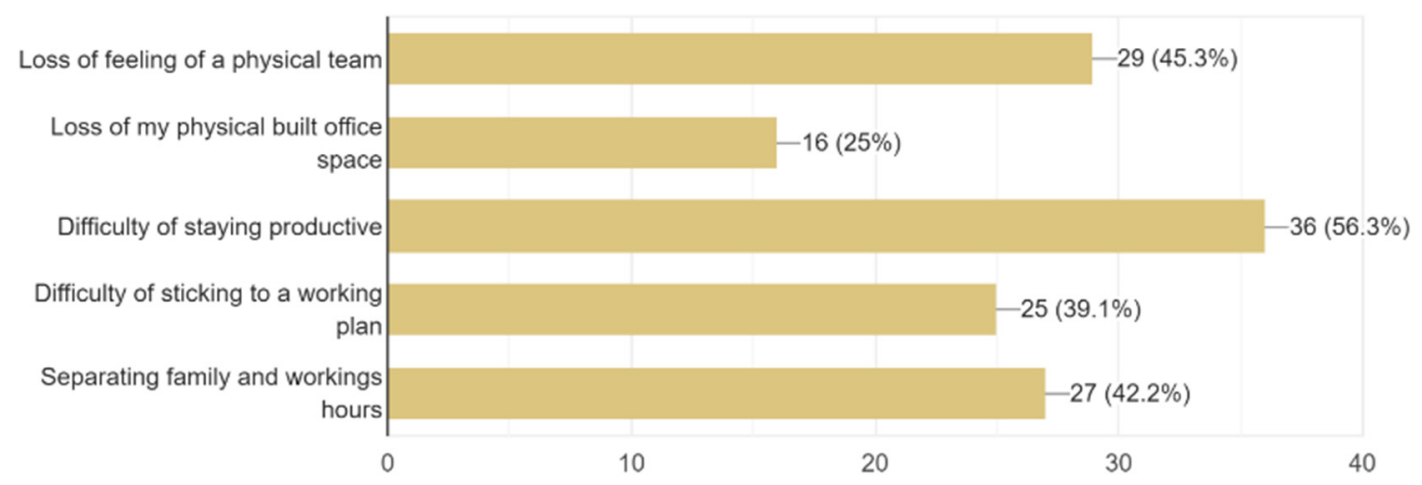

Figure 4. The two most significant difficulties in working from home (WFH). Source: online survey that took place between December 2020 and March 2021. N: 64.

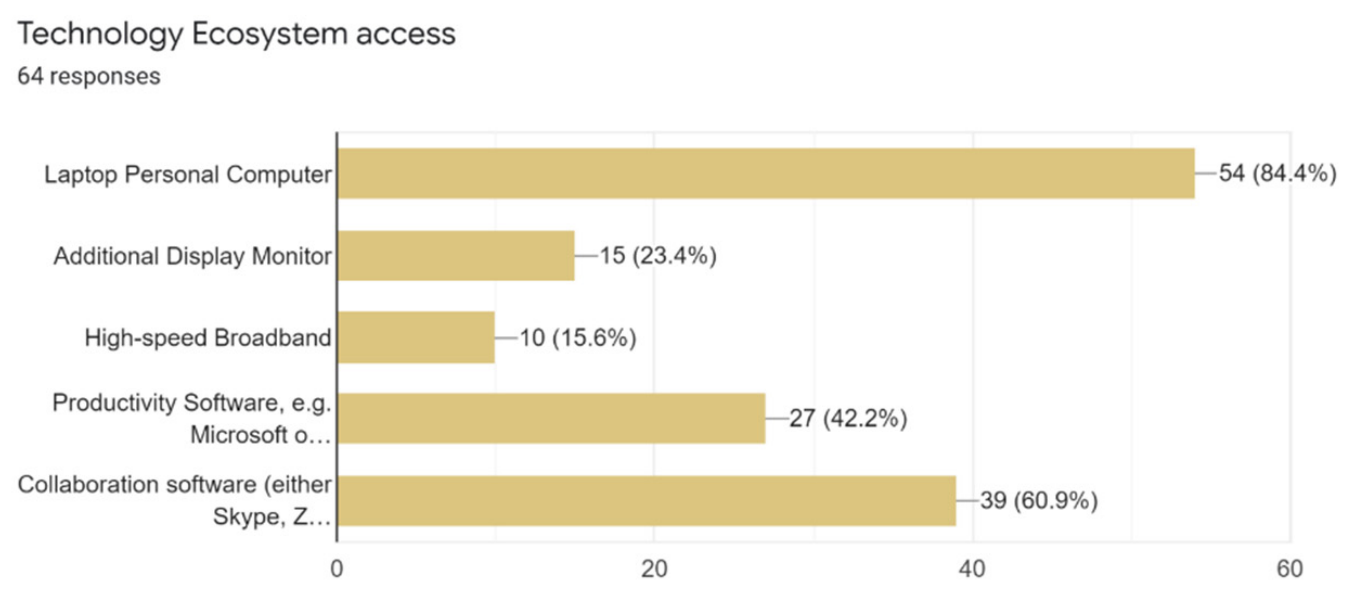

Figure 5. Access to information technology devices in working from home (WFH). Source: online survey that took place between December 2020 and March 2021. N: 64.

Married educated refugees reported being more comfortable with their current income (37\%) than their single counterparts (20\%). There are two divorced persons in our sample that responded that they were just coping with their present income. This relationship is statistically significant at the $10 \%$ level of significance ( $p$-value $<0.1)$, but it is a weak to moderate relationship (Cramer's V $=0.26$ ) (Table S2). Non-Pharmaceutical Interventions (NPI) and lockdowns seem to have affected equally refugees' income regardless of marital status. A great percentage of both married (48\%) and single refugees (46\%) have been strongly affected. The differences in the percentages are not statistically significant (Table S3).

In a gross generalization, we could say that the lower the educational level of refugees, the stronger they have been affected by measures to tackle a virulent disease. In total, $60 \%$ of those with an associate's degree (a level of qualification between high school and university) or bachelor's degree have been strongly affected by the crisis, while $41 \%$ of those with a Master's degree and "only" $25 \%$ of those with a PhD degree have been strongly affected. This relationship has a small chance of arising by chance alone, though it is not statistically significant at the 0.05 level of significance $(p$-value $=0.17)$. The value of Gamma (-0.4) denotes a moderate relationship (Table S4). It is important that WFH affects equally the young and the older respondents. It is moderately challenging for a great percentage of both age groups ( $47 \%$ for younger migrants, $44 \%$ for older), while it is highly challenging for 39\% of the young and the older as well (Table S5). The majority of refugees did not like working from home during the pandemic, and this attitude did not 
change with age (Table S6). In contrast, $70 \%$ of the researchers found the increasing time of WFH in the post-pandemic period favorable and efficient [34].

Lockdowns imposed by governments have not had the same impact on refugees' income. On the one hand, the majority of those working in academia have not been affected at all as far as their income is concerned. Other studies show the researchers' loss of academic work as a potential financial impact due to the need for additional funding for repetition of work affected by lab closures [18]. On the other hand, the majority of those RRs working in other sectors (NGOs, public administration, self-employed) have seen their income reduced during the lockdown (Table S7). The working sector has also played an important role in job security during the pandemic. The majority of those employed in the academic sector were still being employed during the pandemic $(74 \%)$, while the majority of those employed in other sectors became unemployed during the pandemic $(58 \%)$. This relationship is statistically significant ( $p$-value $<0.05)$ but moderately strong $($ Cramer's V $=0.29)$ (Table S8).

\section{Discussion}

With the sudden onset of the pandemic and the strict protection measures, the RRs have faced multiple changes that the crisis has brought about in all areas of life. Almost $15.6 \%$ of the RRs feel the impact of the pandemic on their health and $45 \%$ on their income, whereas $46.9 \%$ find it difficult to live comfortably with their current income and worry about the current health crisis. RRs working in the non-academic sector have had great difficulties in coping with issues, such as unemployment, during the pandemic. It has been found that unemployed refugees and student refugees have experienced economic issues coping with present income, and are extremely anxious that COVID-19 will significantly affect their income and employment [32].

The COVID19 pandemic has caused massive decline in the economic growth of all EU countries, especially the countries hosting RRs [35]. This has caused a change in employment prospects, and a sharp decrease in labor market offers [36]. Furthermore, working from home (WFH) has become the new standard for most of the jobs across different disciplines [3,11]. As for RRs, WFH has become a major issue. Many of them live in crowded home spaces [37] with many family members in most cases. Thus, there is limited space to set up a home office for remote work. Although social communication tools have been improved drastically over the past year, the aforementioned issues have caused massive distress factors to the RRs' lives. In contrast to the findings of recent studies [38], RRs have been struggling to find a work-life balance in WFH and to remain productive.

During the COVID19 pandemic, the asylum procedures over the EU have been affected drastically. In total, $87.3 \%$ of the respondents in the current study believe that the COVID-19 pandemic has had negative consequences on asylum procedures. Many of the applications have been put on hold for many months [39]. During the COVID-19 pandemic, the asylum seekers have been left in limbo by the governmental bodies $[40,41]$.

The social distancing that the pandemic brought to RRs' lives generated serious obstacles to create new networks of contacts, accessing job information and obtaining employment [24]. Proactivity is suggested as an important integration process (contact with locals, learn the local language, adaptation of local norms and practices, recognize training opportunities) [42]. Language is a serious barrier for refugees with no or limited English skills. Moreover, the majority of job applications must be in the language of the host country or in the English language, thus resulting in the almost complete exclusion of the non-English speaking refugee population (Tzoraki et al., 2019).

On the one hand, priority was given to the protection of public health, ignoring the need for improving infrastructures and protecting mental health [43], intensifying interpreters' (or cultural mediators') contribution to collective accommodation centers [44] and protecting jobs during COVID-19 [45]. Less attention has been paid to the loss of lifestyle due to decreased physical activity [46] and increased likelihood for stress and mental health problems $[17,47,48]$. Being employed on precarious contracts or unemployed, 
refugees live in overcrowded camps or houses, with limited chances for social distancing, poor nutrition and sanitation [49].

On the other hand, many digital tools have been developed to support RRs to restart their research career. The Science4Refugees (S4R) tool was recently been launched by the Euraxess-EU [50]. This tool helps RRs look for places and opportunities at various European universities. Furthermore, the BRiDGE II project has launched a mentoring program that allows RRs to look for mentorship either by finding peer mentors or other types of mentors that can help RRs in their path back into research life [29]. Financially, there have been efforts by multiple groups, including our BRiDGE II group, to advocate for proper funding mechanisms for refugee scientists. In Germany, multiple funding mechanisms have been established. The Philipp-Schwartz Initiative of the Alexander von Humboldt Foundation is one of them. They help RRs, who have a PhD in their pursuit to re-enter academic life by providing more than two years of funding as a post-doctoral researcher. Furthermore, the German Research Foundation (DFG) facilitates DFG-funded researchers to access extra funding for a RR as a PhD candidate. SCIREA and BRiDGE II projects provided funding for internships across Europe before the pandemic, and some online internships have been provided throughout the pandemic. The European Commission refused to grant paid extensions to Marie Skłodowska Curie (MSCA) fellows, who had to put their research on hold during the coronavirus lockdown [51].

\section{Practical Implication}

The main recommendations for the public authorities are the following:

(1) Contractual aspects of employer-employee relationships; existing projects in academia that support RRs should be extended and new projects for RRs should be approved, since most RRs are peripheral workers with precarious contracts.

(2) Prospects and career advancement; authorities should accelerate decisions about the residential status of RRs or give at least a 3 year extension of their residence and foster RRs' careers by supporting programs that provide advice and support. In addition, a new process should be developed to identify and support RRs at their earliest stage of the asylum process.

(3) Lack of language skills is a significant barrier to the integration of RRs in the labor market. Enroll RRs in language courses to reach high/advanced level.

(4) Prolongation of contracts or new scholarships should be offered. This is required to keep RRs on track and motivate them to persist. Moreover, this could create a kind of competition among RRs to do their best.

(5) Provision of the needed technology (computers, internet access); this is essential for RRs, especially for newcomers. It is very hard to get a device (computer) and internet access without support from the authorities. Without these tools, it is impossible for RRs to start over.

(6) Simplification of certificate recognition; it is time consuming and highly costly to prepare the documents for recognition with the requisite stamps, such as, the "apostille" according to the Hague Convention of 1961. Especially under COVID-19 restrictions, the continued use of signed and stamped hardcopies of the documents has become excessively restrictive and time consuming. Moreover, a global database of a list of accredited universities should be generated, where there will be a quality assurance information system that evaluates and certifies the quality standards for each university. A German version of this database has already been in place for years, but it is not updated for the Arabic countries such as Syria [52].

(7) Encourage private companies to employ refugees. Regular "matching events" should be organized between the private sector and RRs in order to provide RRs with the opportunity to work outside of academia.

(8) Provision of psychological support. Throughout the pandemic year, many refugees and, especially RRs, have gone through a lot of stress, and many of them are suffering from depression. Up until now, psychological and social support for RRs has been 
very rare. There are a couple of organizations that have been actively helping refugees, including RRs, but the extent of the support they can offer is still inadequate and needs to be enhanced and increased.

\section{Conclusions}

The socioeconomic and health consequences of the COVID-19 pandemic have increased RRs' vulnerability, especially those found in asylum procedures. It was observed that RRs were greatly worried about the current health crisis, insecure about health protection and lacked resources to effectively WFH, in particular, through lack of working space and access to IT hardware and software. The decrease of income, the loss of employment and the difficulty with staying productive in working from home are important concerns. Recommendations are provided to extend temporary contracts and to prioritize the administration of asylum procedures, as well as various measures to improve RRs' integration such as online advanced language courses and provision of technological hardware and software licenses.

Supplementary Materials: The following are available online at https://www.mdpi.com/article/ 10.3390/soc11030071/s1, Table S1: The questionnaire about the impact of COVID-19 on the work, income and asylum procedures of refugee researchers (RRs), Table S2: Current income and marital status, Table S3: How much income has been affected during crisis, broken down by marital status. Table S4: How much income has been affected during crisis, broken down by educational level. Table S5: Adaptation to working from home versus age, Table S6: Attitude towards fulltime working from home vs. age, Table S7: Impact of lockdown on income in working sector, Table S8: Impact of lockdown on employment in working sector.

Author Contributions: Conceptualization, O.T. and A.Ć.; methodology, O.T., E.A., V.G. and A.Ć.; investigation, O.T., A.Ć., S.Y., A.H. and H.H.; resources, S.D. and M.B.; writing-original draft preparation, O.T., V.G., M.T. and B.C.; writing—review and editing, all authors; visualization, O.T.; supervision, O.T.; project administration, E.A.; funding acquisition, S.D. and M.B. All authors have read and agreed to the published version of the manuscript.

Funding: This research was funded by Bridge for Researchers in Danger going to Europe Step II (BRIDGEII project), grant number $824601 \mathrm{https}$ / / cordis.europa.eu/project/id/824601.

Conflicts of Interest: The authors declare no conflict of interest.

\section{References}

1. COVID-19 Google News. 2021. Available online: https://news.google.com/covid19/map?hl=en-US\&mid=\%2Fm\%2F035qy\& gl=US\&ceid=US\%3Aen (accessed on 25 April 2021).

2. Villela, E.F.D.M.; López, R.V.M.; Sato, A.P.S.; de Oliveira, F.M.; Waldman, E.A.; Bergh, R.V.D.; Fodjo, J.N.S.; Colebunders, R. COVID-19 outbreak in Brazil: Adherence to national preventive measures and impact on people's lives, an online survey. BMC Public Health 2021, 21, 1-10. [CrossRef]

3. Arntz, M.; Ben Yahmed, S.; Berlingieri, F. Working from Home and COVID-19: The Chances and Risks for Gender Gaps. Intereconomics 2020, 55, 381-386. [CrossRef] [PubMed]

4. Kelly, J. The New "COVID-19" Home Office Worker: Evolving Computer-Human Interactions and the Perceived Value of Workplace Technology. Tech. Soc. Sci. J. 2020, 13, 575-581. [CrossRef]

5. OECD. Adapting to Technological and Societal Disruption. In Science, Technology and Innovation Outlook Report; OECD Publishing: Paris, France, 2018.

6. UNHCR. UNHCR Operational Portal-Meditteranean Situation. 2021. Available online: https://data2.unhcr.org/en/situations/ mediterranean (accessed on 17 March 2021).

7. Bloom, N.; Liang, J.; Roberts, J.; Ying, Z.J. Does Working from Home Work? Evidence from a Chinese Experiment. Q. J. Econ. 2015, 130, 165-218. [CrossRef]

8. Monteiro, N.P.; Straume, O.R.; Valente, M. The Effects of the Digital Transformation on the Economics Workplace and the Labor Market. Does Remote Work Improve or Impair Firm Labour Productivity? Longitudinal Evidence from Portugal. CESifo Working Paper No 7991 2019. Available online: https:/ /www.cesifo.org/en/publikationen/2019/working-paper/does-remote-workimprove-or-impair-firm-labour-productivity (accessed on 26 June 2021).

9. Dutcher, E.G. The effects of telecommuting on productivity: An experimental examination. The role of dull and creative tasks. J. Econ. Behav. Organ. 2012, 84, 355-363. [CrossRef] 
10. Holgersen, H.; Jia, Z.; Svenkerud, S. Who and how many can work from home? Evidence from task descriptions. J. Labour Mark. Res. 2021, 55, 1-13. [CrossRef]

11. Irlacher, M.; Koch, M. Working from Home, Wages, and Regional Inequality in the Light of COVID-19. Jahrbücher für Nationalökonomie und Statistik 2021, 241, 373-404. [CrossRef]

12. Gottlieb, C.; Grobovšek, J.; Poschke, M.; Saltiel, F. Working from home in developing countries. Eur. Econ. Rev. 2021, 133, 103679. [CrossRef]

13. Yamamura, E.; Tsustsui, Y. The impact of closing schools on working from home during the COVID-19 pandemic: Evidence using panel data from Japan. Rev. Econ. Househ. 2021, 19, 41-60. [CrossRef]

14. Viglione, G. Are women publishing less during the pandemic? Here's what the data say. Nature 2020, 581, 365-366. [CrossRef]

15. Kramer, A.; Kramer, K.Z. The potential impact of the COVID-19 pandemic on occupational status, work from home, and occupational mobility. J. Vocat. Behav. 2020, 119, 103442. [CrossRef] [PubMed]

16. King, E.M.; Randolph, H.L.; Floro, M.S.; Suh, J. Demographic, health, and economic transitions and the future care burden. World Dev. 2021, 140, 105371. [CrossRef]

17. Blom, V.; Lönn, A.; Ekblom, B.; Kallings, L.V.; Väisänen, D.; Hemmingsson, E.; Andersson, G.; Wallin, P.; Stenling, A.; Ekblom, Ö.; et al. Lifestyle Habits and Mental Health in Light of the Two COVID-19 Pandemic Waves in Sweden, 2020. Int. J. Environ. Res. Public Health 2021, 18, 3313. [CrossRef] [PubMed]

18. Korbel, J.O.; Stegle, O. Effects of the COVID-19 pandemic on life scientists. Genome Biol. 2020, 21, 1-5. [CrossRef]

19. Van Fan, Y.; Jiang, P.; Hemzal, M.; Klemeš, J.J. An update of COVID-19 influence on waste management. Sci. Total Environ. 2021, 754, 142014. [CrossRef]

20. Donzelli, G.; Cioni, L.; Cancellieri, M.; Morales, A.L.; Suárez-Varela, M.M. The Effect of the Covid-19 Lockdown on Air Quality in Three Italian Medium-Sized Cities. Atmosphere 2020, 11, 1118. [CrossRef]

21. Else, H. How a torrent of COVID science changed research publishing-In seven charts. Nature 2020, 588, 553. [CrossRef] [PubMed]

22. Myers, K.R.; Tham, W.Y.; Yin, Y.; Cohodes, N.; Thursby, J.G.; Thursby, M.C.; Schiffer, P.; Walsh, J.T.; Lakhani, K.R.; Wang, D. Unequal effects of the COVID-19 pandemic on scientists. Nat. Hum. Behav. 2020, 4, 880-883. [CrossRef] [PubMed]

23. Matthews, M.; del Álamo Rodriguez, D.; Gray, A. A conversation on the effects of the COVID-19 pandemic on junior researchers' careers with funders and university leaders. Nat. Commun. 2021, 12, 2096. [CrossRef]

24. Kowal, M.; Sorokowski, P.; Sorokowska, A.; Lebuda, I.; Groyecka-Bernard, A.; Białek, M.; Kowalska, K.; Wojtycka, L.; Olszewska, A.M.; Karwowski, M. Dread in Academia-How COVID-19 affects science and scientists. Anthropol. Rev. 2020, 83, 387-394. [CrossRef]

25. Falkenhain, M.; Flick, U.; Hirseland, A.; Naji, S.; Seidelsohn, K.; Verlage, T. Setback in labour market integration due to the COVID-19 crisis? An explorative insight on forced migrants' vulnerability in Germany. Eur. Soc. 2021, 23, S448-S463. [CrossRef]

26. Hillmann, F.; Koca, B.T. "By women, for women, and with women": On the integration of highly qualified female refugees into the labour Markets of Berlin and Brandenburg. Comp. Migr. Stud. 2021, 9, 1-18. [CrossRef]

27. Bagavos, C.; Kourachanis, N. Civil Society Organizations and Labour Market Integration for Refugees and Asylum Seekers in Greece. Volunt. Int. J. Volunt. Nonprofit Organ. 2021, 1-11. [CrossRef]

28. Irastorza, N.; Bevelander, P. Skilled Migrants in the Swedish Labour Market: An Analysis of Employment, Income and Occupational Status. Sustainability 2021, 13, 3428. [CrossRef]

29. BRIDGE II. 2021. Available online: https://www.uni-bielefeld.de/uni/profil/international/bridgeprojects/bridge2/index.xml (accessed on 17 March 2021).

30. SCIREA. 2021. Available online: http:/ / scirea.aegean.gr/index.php (accessed on 17 March 2021).

31. Grasso, M.; Klicperová-Baker, M.; Koos, S.; Kosyakova, Y.; Petrillo, A.; Vlase, I. The impact of the coronavirus crisis on European societies. What have we learnt and where do we go from here?-Introduction to the COVID volume. Eur. Soc. 2021, 23, S2-S32. [CrossRef]

32. Cimpoeru, S.; Roman, M.; Kobeissi, A.; Mohammad, H. How are European Migrants from the MENA Countries Affected by COVID-19? Insights from an Online Survey. J. Soc. Econ. Stat. 2020, 9, 128-143. [CrossRef]

33. Peroune, D.L. Tacit knowledge in the workplace: The facilitating role of peer relationships. J. Eur. Ind. Train. 2007, 31, 244-258. [CrossRef]

34. Aczel, B.; Kovacs, M.; van der Lippe, T.; Szaszi, B. Researchers working from home: Benefits and challenges. PLoS ONE 2021, 16, e0249127. [CrossRef] [PubMed]

35. König, M.; Winkler, A. COVID-19 and Economic Growth: Does Good Government Performance Pay Off? Intereconomics 2020, 55, 224-231. [CrossRef] [PubMed]

36. Witteveen, D.; Velthorst, E. Economic hardship and mental health complaints during COVID-19. Proc. Natl. Acad. Sci. USA 2020, 117, 27277-27284. [CrossRef]

37. Cassidy, K. Solidarity in Pandemic Times: Asylum Seekers in Forced Accommodation during COVID-19. Fuse: Centre for Translational Research in Public Health COVID-19. Semin. Ser. 2020. Available online: http://www.fuse.ac.uk/media/sites/ researchwebsites/fuse/Kathryn\%20Cassidy\%20presentation\%20July\%202020.pdf (accessed on 26 June 2021).

38. Ipsen, C.; van Veldhoven, M.; Kirchner, K.; Hansen, J.P. Six Key Advantages and Disadvantages of Working from Home in Europe during COVID-19. Int. J. Environ. Res. Public Health 2021, 18, 1826. [CrossRef] 
39. EASO. COVID-19 Emergency Measures in Asylum and Reception Systems, Public-Issue No. 3, 41 pages, 7 December 2020.2020. Available online: https:/ / easo.europa.eu/sites/default/ files/publications/COVID-19\%20emergency\%20measures \%20in $\% 20$ asylum\%20and\%20reception\%20systems-December-2020_new.pdf (accessed on 26 June 2021).

40. Elisabeth, M.; Maneesh, P.-S.; Michael, S. Refugees in Sweden During the Covid-19 Pandemic-The Need for a New Perspective on Health and Integration. Front. Public Health 2020, 8, 574334. [CrossRef]

41. Doliwa-Klepacka, A.; Zdanowicz, M. The European Union Current Asylum Policy: Selected Problems in the Shadow of COVID-19. Int. J. Semiot. Law Rev. Int. Sémiotique Jurid. 2020, 1-17. [CrossRef]

42. Eggenhofer-Rehart, P.M.; Latzke, M.; Pernkopf, K.; Zellhofer, D.; Mayrhofer, W.; Steyrer, J. Refugees' career capital welcome? Afghan and Syrian refugee job seekers in Austria. J. Vocat. Behav. 2018, 105, 31-45. [CrossRef]

43. Pinzón-Espinosa, J.; Valdés-Florido, M.J.; Riboldi, I.; Baysak, E.; Vieta, E. The COVID-19 Pandemic and Mental Health of Refugees, Asylum Seekers, and Migrants. J. Affect. Disord. 2021, 280, 407-408. [CrossRef]

44. Biddle, L.; Jahn, R.; Perplies, C.; Gold, A.W.; Rast, E.; Spura, A.; Bozorgmehr, K. COVID-19 in collective accommodation centres for refugees: Assessment of pandemic control measures and priorities from the perspective of authorities. Bundesgesundheitsblatt Gesundh. Gesundh. 2021, 64, 342-352. [CrossRef] [PubMed]

45. Betcherman, G.; Giannakopoulos, N.; Laliotis, I.; Pantelaiou, I.; Testaverde, M.; Tzimas, G. Reacting Quickly and Protecting Jobs: The Short-Term Impacts of the COVID-19 Lockdown on the Greek Labor Market; Global Labor Organization (GLO): Essen, Germany, 2020.

46. Gallè, F.; Sabella, E.A.; Ferracuti, S.; De Giglio, O.; Caggiano, G.; Protano, C.; Valeriani, F.; Parisi, E.A.; Valerio, G.; Liguori, G.; et al. Sedentary Behaviors and Physical Activity of Italian Undergraduate Students during Lockdown at the Time of COVID-19 Pandemic. Int. J. Environ. Res. Public Health 2020, 17, 6171. [CrossRef] [PubMed]

47. Byrom, N. COVID-19 and the Research Community: The Challenges of Lockdown for Early-Career Researchers. eLife J. 2020. Available online: https:/ / elifesciences.org/articles/59634 (accessed on 26 June 2021).

48. Byrom, N.; Metcalfe, J. Impact of COVID 19 on Doctoral and Early Career Researchers. Figshare Dataset 2020. Available online: https: / figshare.com/articles / dataset/Impact_of_COVID_19_on_Doctoral_and_Early_Career_Researchers/12361493 (accessed on 26 June 2021).

49. Abbasi-Shavazi, M.J. COVID-19, economic recession, and the Refugee situation. Int. Migr. 2021, 59, 289-292. [CrossRef]

50. EURAXESS. Science4Refugees-Welcome Refugee Researchers and Students Looking for a Suitable Job! 2021. Available online: https:/ / euraxess.ec.europa.eu/jobs/science4refugees (accessed on 23 March 2021).

51. Zubașcu, F. Marie Curie Researchers ‘Betrayed' by Commission's Refusal to Extend Costs. Sci. I Bus. J. 2020. Available online: https://sciencebusiness.net/covid-19/news/marie-curie-researchers-betrayed-commissions-refusal-extend-costs (accessed on 23 March 2021).

52. ANABIN. Das Infoportal zu Ausländischen Bildungsabschlüssen. Available online: https://anabin.kmk.org/ (accessed on 8 June 2021). 